\title{
Spontaneous Unitary Synaptic Activity in CA1 Pyramidal Neurons during Early Postnatal Development: Constant Contribution of AMPA and NMDA Receptors
}

\author{
Laurent Groc, Bengt Gustafsson, and Eric Hanse \\ Institute of Physiology and Pharmacology, Department of Physiology, Göteborg University, 40530 Göteborg, Sweden
}

\begin{abstract}
Maturation of the glutamatergic synapse is thought to require the incorporation of AMPA receptors at pure NMDA synapses, also called "silent" synapses. However, the relative number of silent synapses at different developmental stages, and even the concept that silent synapses lack AMPA receptors, is actively debated. In the present work, spontaneous synaptic events were used to investigate the relative contribution of synaptic AMPA and NMDA receptor-mediated transmission in CA1 pyramidal cells during the early postnatal development. Spontaneous postsynaptic currents, mediated by AMPA and NMDA
\end{abstract}

After the formation of synaptic contacts, the maturation of glutamatergic synapses has been proposed to be sequential in the sense that NMDA receptor-mediated signaling develops before the AMPA receptor-mediated one. In support of this notion, both electrophysiological (Durand et al., 1996; Liao and Malinow, 1996; Hsia et al., 1998) and immunohistochemical (Liao et al., 1999; Petralia et al., 1999; Takumi et al., 1999) studies in the hippocampus have suggested that the majority of synapses in the neonatal slice preparation are pure NMDA synapses. During the first two postnatal weeks, the relative frequency of these "silent" synapses decreases markedly (Durand et al., 1996; Liao and Malinow, 1996; Hsia et al., 1998), and these synapses can be converted to dual NMDA and AMPA receptor-containing synapses in an activity-dependent manner (Isaac et al., 1995; Liao et al., 1995; Durand et al., 1996). Finally, the neonatal hippocampus exhibits an endogenous neural activity potentially supporting such activity-dependent conversion (Ben Ari et al., 1989; Garaschuk et al., 1998).

However, some studies have questioned this hypothesis. It has been suggested that the existence of silent synapses is merely a consequence of low recording temperatures, because of either an enhanced spillover of glutamate from neighboring synapses (Asztely et al., 1997) or a very low release probability (Gasparini et al., 2000). Moreover, other immunohistochemical (Friedman et al., 2000) and electrophysiological (Cottrell et al., 2000) studies have indicated that nascent hippocampal glutamatergic synapses express both AMPA and NMDA receptors. Rather than an incorporation of AMPA receptors, a change in the kinetics of presyn-

Received Jan. 28, 2002; revised April 2, 2002; accepted April 16, 2002.

This project was supported by Swedish Medical Research Council Project Numbers 12600 and 01580, the Swedish Society of Medicine, and Harald Jeanson's Foundation. L.G. was supported by the Institut National de la Santé et de la Recherche Médical. We thank Pontus Wasling for critical comments.

Correspondence should be addressed to Dr. Laurent Groc, Göteborg University, Department of Physiology, Box 432, Medicinaregatan 11, 40530 Göteborg, Sweden. E-mail: laurent.groc@physiol.gu.se.

Copyright (C) 2002 Society for Neuroscience $\quad 0270-6474 / 02 / 225552-11 \$ 15.00 / 0$ receptors, were recorded from visualized CA1 pyramidal neurons over the first postnatal week. AMPA/NMDA ratio for frequency was close to one, and, importantly, it was constant over the first postnatal week. These findings suggest that the vast majority of nascent glutamatergic synapses express both functional AMPA and NMDA receptors in the neonatal hippocampus.

Key words: AMPA receptor; NMDA receptor; neonate hippocampus; silent synapse; development; spontaneous activity

aptic exocytosis of glutamatergic vesicles was proposed as the mechanism to explain the developmental decrease in silent synapses (Choi et al., 2000; Renger et al., 2001). Finally, among the cells exhibiting glutamate signaling at birth, the majority exhibited both NMDA and AMPA EPSCs (Tyzio et al., 1999).

As indicated above, the existence and/or the proportion of silent synapses in the developing synaptic network is actively debated. Because previous electrophysiological studies have used evoked synaptic responses, we decided to use a more representative, but still direct, method of evaluating the relative contribution of AMPA and NMDA receptor-mediated signaling by monitoring spontaneous synaptic currents. With this method, we found that the frequency of AMPA spontaneous EPSCs (sEPSCs) is almost the same as that of NMDA sEPSCs. Importantly, this AMPA/NMDA frequency ratio did not change over the first postnatal week. This result supports the hypothesis that newly formed glutamatergic synapses express both AMPA and NMDA receptors (Friedman et al., 2000; Renger et al., 2001).

\section{MATERIALS AND METHODS}

Slice preparation. Hippocampal slices were prepared from postnatal day 1 (P1) to P8 Wistar rats. Rats were decapitated, and the brain was removed and placed in ice-cold solution composed of (in mM): $124 \mathrm{NaCl}, 3.0 \mathrm{KCl}$, $2 \mathrm{CaCl}_{2}, 6 \mathrm{MgCl}_{2}, 1.25 \mathrm{NaH}_{2} \mathrm{PO}_{4}, 26 \mathrm{NaHCO}_{3}$, and 10 glucose. Transverse hippocampal slices $(300 \mu \mathrm{m})$ were cut using a vibrating tissue slicer (Campden Instruments, Loughborough, UK), transferred to a holding chamber, and stored at $28^{\circ} \mathrm{C}$ for at least $30 \mathrm{~min}$. For recording, slices were individually transferred to a recording chamber in which they were perfused at $30-32^{\circ} \mathrm{C}$. The extracellular solution contained (in mM): 124 $\mathrm{NaCl}, 3.0 \mathrm{KCl}, 4 \mathrm{CaCl}_{2}, 4 \mathrm{MgCl}_{2}, 1.25 \mathrm{NaH}_{2} \mathrm{PO}_{4}, 26 \mathrm{NaHCO}_{3}$, and 10 glucose. GABAergic PSCs were blocked by $10 \mu \mathrm{M}$ bicuculline.

Patch-clamp recordings. CA1 pyramidal cells were visually identified using infrared-differential interference contrast videomicroscopy [Hamamatsu (Shizouka, Japan) and Nikon (Tokyo, Japan)], and wholecell patch-clamp recordings were performed with an EPC-9 patch-clamp amplifier (Heka, Lambrecht, Germany). The pipette solution contained (in mM): $120 \mathrm{Cs}$-gluconate, 20 tetraethylammonium-hydroxide, $2 \mathrm{NaCl}, 5$ QX-314, $4 \mathrm{Mg}$-ATP, 0.4 Na-GTP, 10 EGTA, and 10 HEPES (solution was $280-300$ mOsm with a $\mathrm{pH}$ of 7.3 , adjusted with gluconic acid). In 
experiments in which evoked EPSCs were recorded (see below), $0.2 \mathrm{~mm}$ EGTA (instead of $10 \mathrm{~mm}$ ) was used. Patch pipettes (1.5 mm outer diameter, $0.86 \mathrm{~mm}$ inner diameter; borosilicate; Clark Electrochemical Instruments, Pangbourne, UK) were pulled using a horizontal puller (Sutter Instruments, Novato, CA). They had a resistance of 3-6 M $\Omega$ and were not polished or coated. The liquid junction potential $(8.4 \mathrm{mV})$ was not corrected. The series resistance, which was continuously monitored during the experiments using a $10 \mathrm{mV}$ hyperpolarizing pulse, varied in different cells between 6 and $20 \mathrm{M} \Omega(n=60)$. Recordings included for analysis were collected during periods of stable series resistance. Recordings with series resistance $>20 \mathrm{M} \Omega$ were discarded. The leak current at the holding potential of $-80 \mathrm{mV}$ averaged $-33 \pm 5 \mathrm{pA}(n=60)$. Recordings with leak current more than $-80 \mathrm{pA}$ were discarded. Responses were filtered at $2 \mathrm{kHz}$ and sampled at $10 \mathrm{kHz}$. The input resistance of the cells averaged $0.81 \pm 0.05 \mathrm{G} \Omega(n=60)$. The capacitance of the cells averaged $15.6 \pm 0.8 \mathrm{pF}(\mathrm{P} 1-\mathrm{P} 8 ; n=60)$ and showed a positive correlation with increasing age $(r=0.49 ; p<0.001)$. When examined in a subset of the cells $(n=16)$, the average AMPA sEPSC amplitude from a given cell did not correlate with series resistance $(r=$ $0.12 ; p>0.05)$, cell capacitance $(r=0.1 ; p>0.05)$, or sEPSC rise time $(r=0.104 ; p>0.05)$. The coefficient of variation (CV) was calculated as follows: ( $\left.\mathrm{SD}_{\text {sEPSCs }}{ }^{2}-\mathrm{SD}_{\text {noise }}{ }^{2}\right)^{0.5} /$ mean sEPSC amplitude.

Analysis of NMDA and AMPA sEPSCs. Spontaneous PSC analysis was based on recordings of at least 60-120 sec duration at a given membrane potential. At the youngest ages (P1-P3), some cells were completely silent (no glutamatergic event detected) (Tyzio et al., 1999). These cells and cells with sEPSCs frequency lower than $0.05 \mathrm{~Hz}$ were not included for additional analysis (all together, 20 of 60 cells). Recordings were transferred into the Mini-Analysis Program (version 5.1.4; Synaptosoft, Decatur, GA) and were checked in segments of 1-4 sec. All events visually judged as EPSCs were manually indicated for additional analysis in the Mini-Analysis Program. During this selection, the settings of the Mini-Analysis Program were set loosely: threshold amplitude, $>3 \mathrm{pA}$; area threshold, $>10 \mathrm{pA} / \mathrm{msec}(50 \mathrm{pA} / \mathrm{msec}$ for NMDA); peak amplitude, $<20 \mathrm{msec}$ of PSC onset; and average baseline before onset, $>10 \mathrm{msec}$. Root mean square (rms) noise at $-80 \mathrm{mV}$ (when AMPA sEPSCs were detected) was 1-3 pA and at $+40 \mathrm{mV}$ (when NMDA sEPSCs were detected) was $1.5-5 \mathrm{pA}$. Recordings in which the rms noise value was $>5$ pA were not analyzed (12 of 40 cells).

Recordings were made at -80 and $+40 \mathrm{mV}$ to separately detect AMPA and NMDA sEPSCs, respectively. To have near-simultaneous detection of AMPA and NMDA sEPSCs, all experiments, in which AMPA and NMDA sEPSCs were compared, were done without any AMPA (or NMDA) receptor antagonists. Because sEPSCs recorded at $+40 \mathrm{mV}$ may consist of both AMPA and NMDA components, the relative contribution of AMPA to the peak amplitude of the compound sEPSC s at $+40 \mathrm{mV}$ was estimated in two ways: first, from extrapolation of AMPA sEPSCs from $-80 \mathrm{mV}$ recordings, because the AMPA current-voltage relationship was linear (compare with Fig. 2); and second, from AMPA sEPSCs recorded at $+40 \mathrm{mV}$ in the presence of the NMDA receptor antagonist, D-2-amino-5-phosphonopentanoic acid (DAP-5) $(75 \mu \mathrm{M})$. The AMPA component was found to represent $14.1 \pm$ $2 \%$ of the peak compound sEPSC amplitude (5.4 msec after onset) recorded at $+40 \mathrm{mV}(4.2 \pm 0.6$ of $29.7 \pm 2.5 \mathrm{pA} ; n=23)$, indicating $\sim 15 \%$ overestimation of the NMDA sEPSC peak amplitude value if an AMPA component is present. On the other hand, because the NMDA sEPSC has decayed little from its peak when the AMPA sEPSC is fully decayed (see Fig. $3 B$ ), the presence or absence of an AMPA component will have little consequence for the detectability of an NMDA sEPSC. The current-voltage relationship of NMDA sEPSCs was recorded with the non-NMDA glutamate receptor antagonist 2,3-dioxo-6-nitro-1,2,3,4tetrahydrobenzo-quinoxaline-7-sulfonamide (NBQX) $(10 \mu \mathrm{M})$ in the bath. The current-voltage relationship of AMPA sEPSCs was recorded with D-AP-5 in the bath. Analysis was performed using both Mini Analysis Program (version 5.1.4; Synaptosoft) and custom software written in Igor Pro (WaveMetrics, Lake Oswego, OR).

Evoked unitary NMDA EPSCs. Minimal stimulation (Raastad, 1995; Stevens and Wang, 1995) (200 $\mu \mathrm{S}, 7-30 \mu \mathrm{A}$ constant current) using a glass pipette filled with extracellular solution $(\approx 0.5 \mathrm{M} \Omega)$ was used to evoke unitary NMDA EPSCs as described previously (Hanse and Gustafsson, 2001). Briefly, short trains (10 impulses, $50 \mathrm{~Hz}, 5 \mathrm{sec}$ between trains), evoked at various stimulation intensities, were used to identify a putative unitary synaptic input. During this procedure, the cell was held at $-80 \mathrm{mV}$, and the evoked AMPA EPSCs were used to determine release probability (in response to the first stimulus in the train) and the number of release events (successes) during the train for that synaptic input. The holding potential was then switch to $+40 \mathrm{mV}$, and NMDA (plus AMPA) EPSCs were evoked using the same train stimulation (in some cases, also single volley stimulation). Release probability and number of successes were found to be the same for AMPA and NMDA EPSCs in these synapses, indicating that these synapses were unitary "dual" ones and that AMPA and NMDA EPSCs were detected to the same extent. The amplitude of evoked NMDA EPSCs was calculated, as for SEPSCs, as the difference between the peak amplitude and the average baseline value $5 \mathrm{msec}$ preceding the stimulus. Amplitude of failure sweeps was calculated in the same manner using the same time points as for the EPSC peak amplitude measurements. Some NMDA recordings were performed at $+50 \mathrm{mV}$ instead of at $+40 \mathrm{mV}$. When the pooled amplitude distribution (see Fig. $6 A$ ) was constructed, NMDA EPSCs obtained at $+50 \mathrm{mV}$ were first scaled by to match those obtained at $+40 \mathrm{mV}$.

In another set of experiments, NMDA EPSCs from silent synapses were recorded $(n=5)$. In these experiments, the cell was held at $+40 \mathrm{mV}$ when establishing the minimal stimulation criteria for a unitary synaptic input. If, when changing the holding potential to $-80 \mathrm{mV}$, no AMPA EPSCs were observed at either low- or high-frequency, stimulation, the synapse was classified as silent (Hanse and Gustafsson, 2001).

Drugs and statistical analysis. D-AP-5 and NBQX were purchased from Tocris Cookson (Bristol, UK). Bicuculline and 6-chloro-3,4-dihydro-32H-1,2-4benzothiadiazine-7-sulfonide-1,1-dioxide (cyclothiazide) were purchased from Sigma (St. Louis, MO). QX-314 was purchased from Alomone Labs (Jerusalem, Israel). Monte Carlo simulations to test for the effect of a limited sampling were performed using custom software written in Igor Pro (WaveMetrics). Data are expressed as mean \pm SEM if not otherwise indicated. Statistical significance of difference between means were calculated with Student's $t$ test. $p<0.05$ was used as the confidence level for all statistical tests.

\section{RESULTS}

\section{Miniature and spontaneous AMPA EPSCs during early postnatal development}

In the neonatal hippocampus, the glutamatergic innervation of pyramidal neurons is sparse (Tyzio et al., 1999), and the frequency of miniature EPSCs (mEPSCs) (TTX-insensitive) is low (Hsia et al., 1998). Previous studies have indicated that CA3 pyramidal neurons connect to CA1 pyramidal neurons with a single release site in the neonatal period (Hsia et al., 1998; Hanse and Gustafsson, 2001). This circumstance would enable us to include also spontaneous action potential-evoked release to increase the frequency of spontaneous quantal events. To test this possibility in our conditions, we compared the amplitude of AMPA sEPSCs in the absence and presence of TTX (500 nM) (Hsia et al., 1998). Figure $1 A$ exemplifies one such experiment that shows recordings of AMPA sEPSCs in the absence and presence of TTX. Although the frequency of AMPA sEPSCs was lower in the presence of TTX, there was no change in their average amplitude (Fig. $1 B$ ). On average, during the first postnatal week, TTX reduced the frequency of AMPA sEPSCs to approximately one-half (Fig. 1D) $(n=14)$, whereas it produced no change in amplitude (Fig. $1 C)(p>0.05 ; n=14)$. Importantly, and consistent with previous findings (Hsia et al., 1998), the amplitude ratio for AMPA sEPSCs recorded in the absence and presence of TTX was close to one and constant from P1 to P8 (Fig. $1 E$ ). This finding is consistent with the view that CA3-CA1 connections consist of a single release site during the early postnatal period (Hsia et al., 1998; Hanse and Gustafsson, 2001), and it implies that action potential-dependent sEPSCs may be used for the evaluation of quantal glutamatergic transmission.

\section{Detection of spontaneous AMPA and NMDA EPSCs}

Our aim was to compare, in the same cell, the frequency of AMPA and NMDA sEPSCs. We first attempted to record AMPA and NMDA responses concomitantly by recording com- 
A
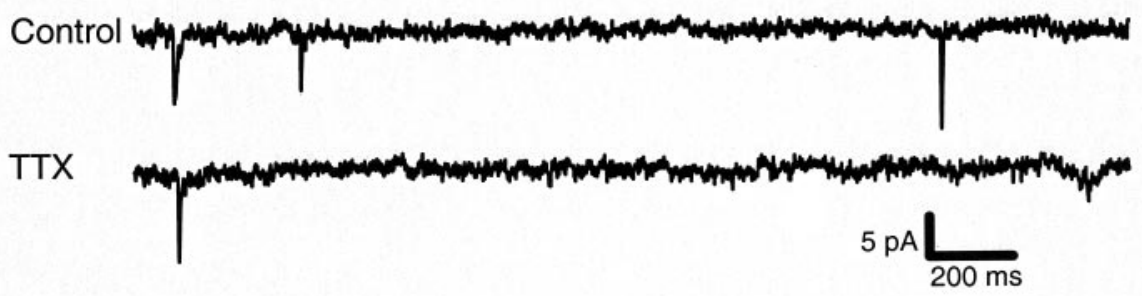

B

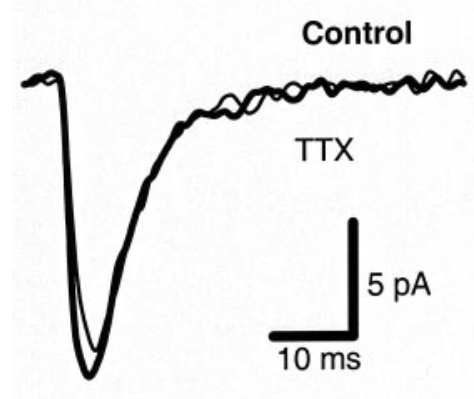

C

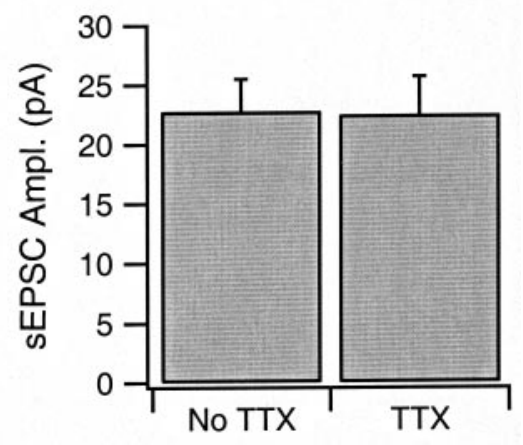

E

Figure 1. Comparison between spontaneous sEPSC (TTX-sensitive) and mEPSC (TTXinsensitive) in CA1 pyramidal cells of $\mathrm{P} 1-\mathrm{P} 8$ rats. $A$, Representative sweeps of sEPSCs (Control, top trace) and mEPSCs [TTX $(0.5 \mu \mathrm{M})$, bottom trace]. Note the decrease in frequency in the presence of TTX. $B$, Average EPSC traces in control (thick line; $n=52$ ) and TTX (thin line; $n=22$ ). $C$, No difference between the average amplitudes of sEPSCs and mEPSCs for P1-P8 cells $(p>0.05 ; n=14)$. $D$, The fraction of mEPSCs in the total population of spontaneous events represents $\sim 50 \%$. E, Ratio for sEPSC over mEPSC amplitudes plotted versus postnatal age. The dashed line indicates a ratio of 1 . The smallest error bars are within the average point symbol (ם).

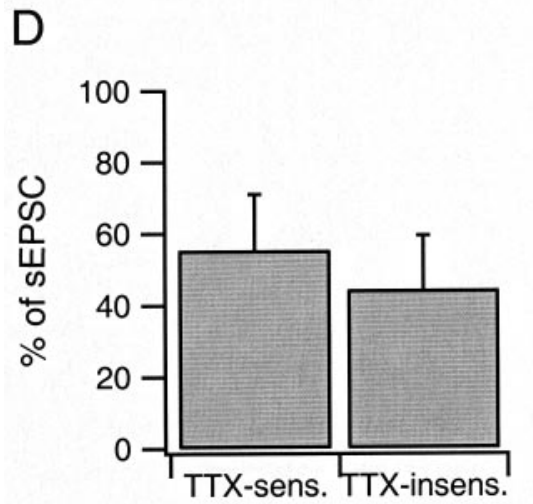

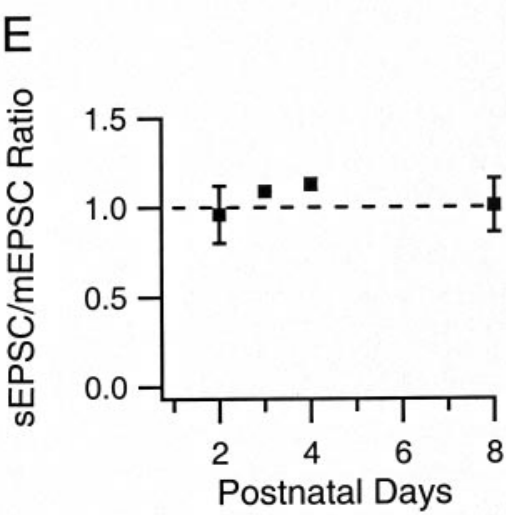

pound AMPA/NMDA sEPSCs at negative holding potentials with reduced or nominally zero extracellular $\mathrm{Mg}^{2+}$. Under these conditions, it was, however, difficult to unambiguously discriminate the AMPA component from the individual compound sEPSCs. To better distinguish the two components, we then attempted to record AMPA and NMDA sEPSCs at different holding potentials. To evaluate optimal recording conditions for detection of these two different sEPSCs, we first recorded AMPA sEPSCs (in the presence of $75 \mu \mathrm{M}$ D-AP-5) and NMDA sEPSCs (in the presence of $10 \mu \mathrm{M}$ NBQX) at varying holding potentials. NMDA and AMPA sEPSCs amplitude-voltage ( $I-V$ ) relationships are shown in Figure 2, $A$ and $B$, respectively ( $n=6$ neurons per group). We then constructed frequency-voltage $(F-V)$ relationships for NMDA and AMPA sEPSCs (Fig. 2C,D, respectively). These relationships indicate that maximal NMDA sEPSC frequency is detected at +40 to $+60 \mathrm{mV}$, and maximal AMPA sEPSC frequency is detected at -80 to $-100 \mathrm{mV}$.

To test whether maximal AMPA sEPSC detection was obtained at $-80 \mathrm{mV}$, cyclothiazide $(100 \mu \mathrm{M})$ was in some of the experiments $(n=4)$ added to the solution. Cyclothiazide signif- icantly increased the AMPA sEPSC amplitude $(+202 \pm 60 \%$ of control; $p<0.05)$ and the decay time $(+255 \pm 72 \%)$ (Fig. $2 E)$. Importantly, despite this twofold increase in amplitude, the AMPA sEPSC frequency at $-80 \mathrm{mV}$ was not significantly affected (Fig. $2 F$ ), substantiating that there is no underestimation of AMPA sEPSC frequency at this holding potential. Evidence substantiating a similar absence of underestimation of NMDA sEPSCs at $+40 \mathrm{mV}$ is described below (see Fig. 6).

As shown in Figure $2 D$, the AMPA sEPSC $F-V$ curve is approximately symmetrical around the reversal level (Fig. 2B), indicating that the actual frequency of AMPA sEPSCs does not depend on whether the holding potential of the postsynaptic cell is positive or negative (Kullmann, 1994; Liao et al., 1995) (but see Niu et al., 1998).

Figure 3 exemplifies, from one cell, recordings of NMDA and AMPA sEPSCs at $+40 \mathrm{mV}$ and at $-80 \mathrm{mV}$, respectively. Figure $3, A$ and $B$, shows individual and average NMDA (top trace) and AMPA (bottom trace) sEPSCs, respectively. The respective amplitude histograms are shown in Figure 3, $C$ and $D$. Average noise levels (root mean square) in these recordings were 2.1 and $3.5 \mathrm{pA}$ 
A
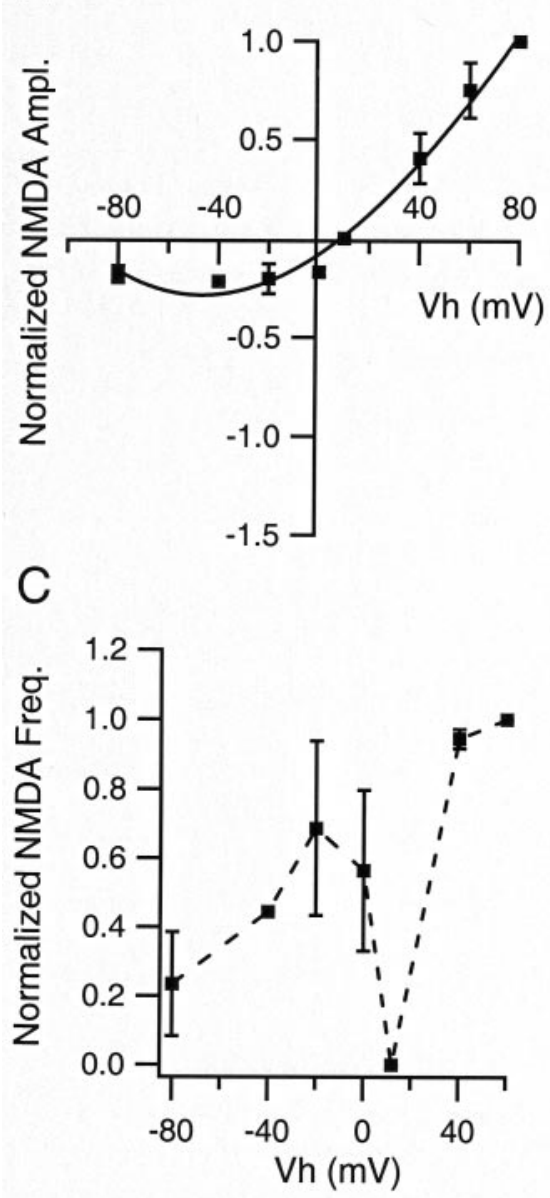

E

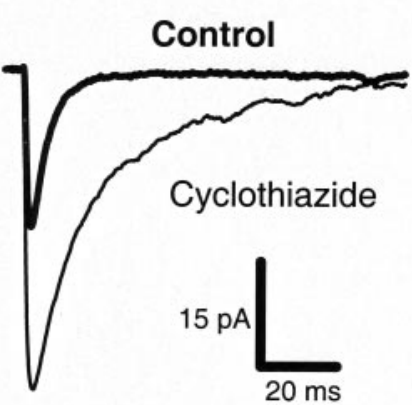

B

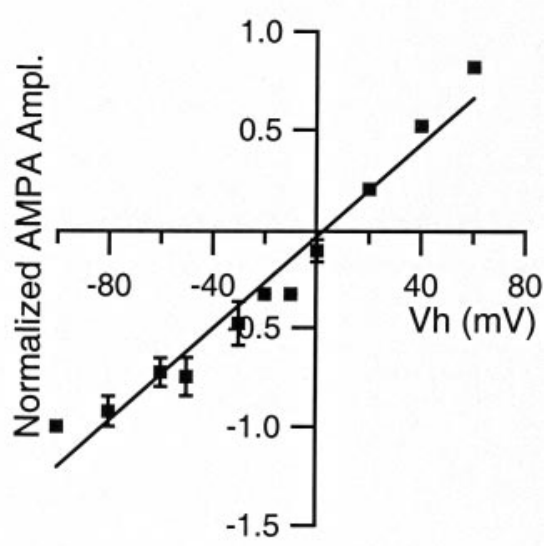

D

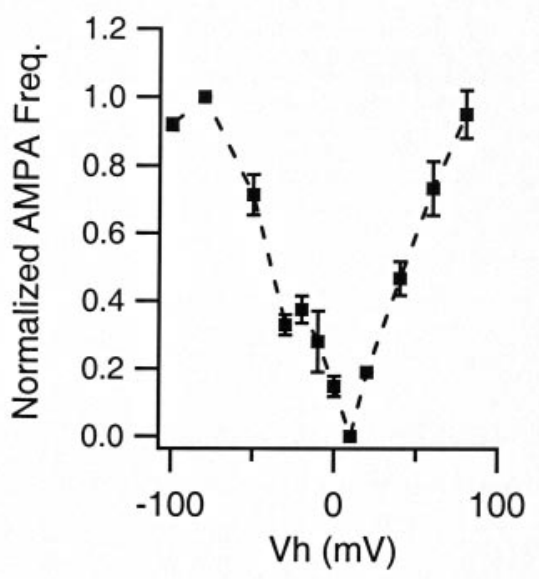

F

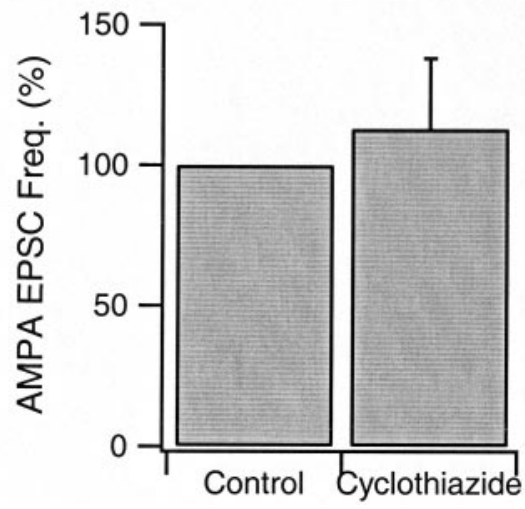

Figure 2. Current-voltage and frequencyvoltage relationships for NMDA and AMPA sEPSCs. $A, B, I-V$ relationship for NMDA sEPSCs $(A$; in the presence of $10 \mu \mathrm{M}$ NBQX) and AMPA sEPSCs $(B$; in the presence of $75 \mu \mathrm{M}$ D-AP-5). The amplitude is normalized to that at +60 and $-80 \mathrm{mV}$, respectively. Curves represent pooled data $(n=6)$. Note the potential overestimation of sEPSC amplitudes for holding potentials close to reversal. This is because of a low signal-to-noise ratio at those potentials, leading to a selection of the largest sEPSCs and, consequently, to an overestimation of averaged amplitude. $C, D, F-V$ relationships for AMPA and NMDA sEPSCs. Curves represent pooled data $(n=6) . F-V$ relationships of sEPSCs shows that an increased membrane polarization (increased EPSC driving force) beyond $+40 \mathrm{mV}$ (NMDA) and beyond $-80 \mathrm{mV}$ (AMPA) does not increase frequency detection. The smallest error bars are within the average point symbol (ם). Note that the detected frequency of AMPA sEPSCs is not dependent on whether the holding potential is negative or positive, because the $F-V$ curve is symmetrical around the reversal potential of the AMPA sEPSC. (Absolute slope for negative and positive holding potentials are not significantly different: $-10.8 \pm 0.8$ and $13.4 \pm 0.6$ normalized units/V, respectively.) E, Average AMPA sEPSC traces in control (thick line; $n=343$ ) and in the presence of cyclothiazide $(100 \mu \mathrm{M}$; thin line; $n=301$ ). Note the increase in AMPA sEPSC amplitude. $F$, In cyclothiazide, the AMPA sEPSC frequency was not significantly different from control $(n=4 ; p>0.05)$. at -80 and $+40 \mathrm{mV}$, respectively. The interevent intervals for these sEPSCs were calculated and plotted as a histogram (100 msec bin) (Fig. $3 E, F)$. The adherence to an exponential fit $(r$ values for logarithmic plots between 0.82 and $0.93 ; n=6$ ) indicates that, in our conditions, sEPSCs did not occur in clusters but randomly and independently of each other (Hsia et al., 1998).

\section{Developmental profile of spontaneous AMPA and NMDA EPSCs}

\section{Frequency}

When examining sEPSCs from 1- to 8-d-old rats, the frequency of these events varied among the cells from 0.05 to $2.5 \mathrm{~Hz}$ for AMPA sEPSCs $(n=40)$ and from 0.05 to $2.6 \mathrm{~Hz}$ for the NMDA ones $(n=28)$. On average, the frequency of AMPA and NMDA sEPSCs was $0.90 \pm 0.12$ and $0.74 \pm 0.13 \mathrm{~Hz}$, respectively. Thus, in this period, NMDA receptors appear not to contribute significantly more than AMPA receptors to spontaneous synaptic transmission.

When examined as a function of postnatal age, there was, on average, a twofold to threefold increase in the frequency of both AMPA (Fig. 4A) $(r=0.40 ; p<0.05 ; n=40)$ and NMDA sEPSCs (Fig. $4 B)(r=0.49 ; p<0.05 ; n=28)$. This increase in frequency may reflect an increase in the number of synapses per cell rather than an increase in the frequency of action potentials, because a similar trend was evident also for mEPSCs (i.e., in the 
A

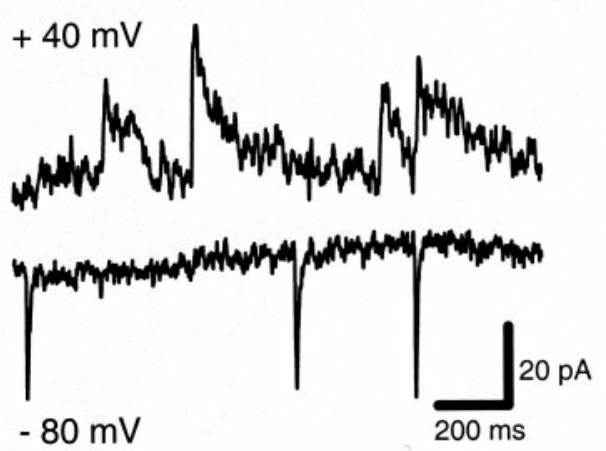

C

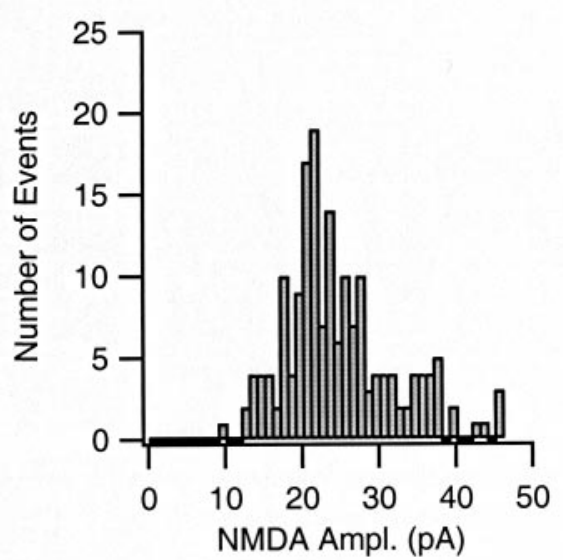

$E$

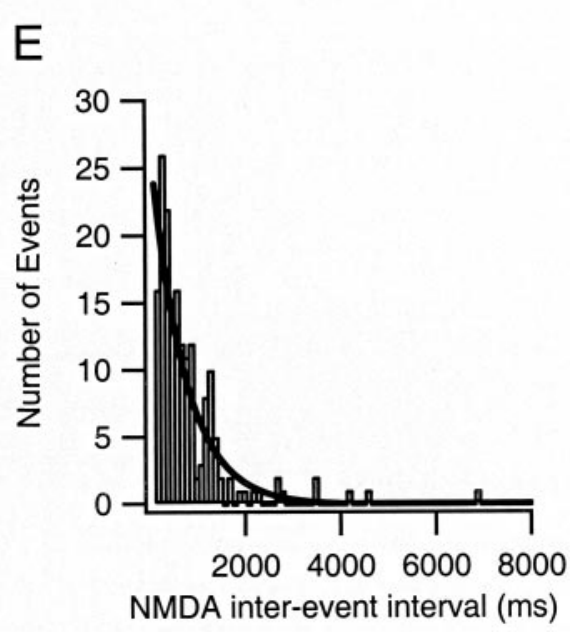

B
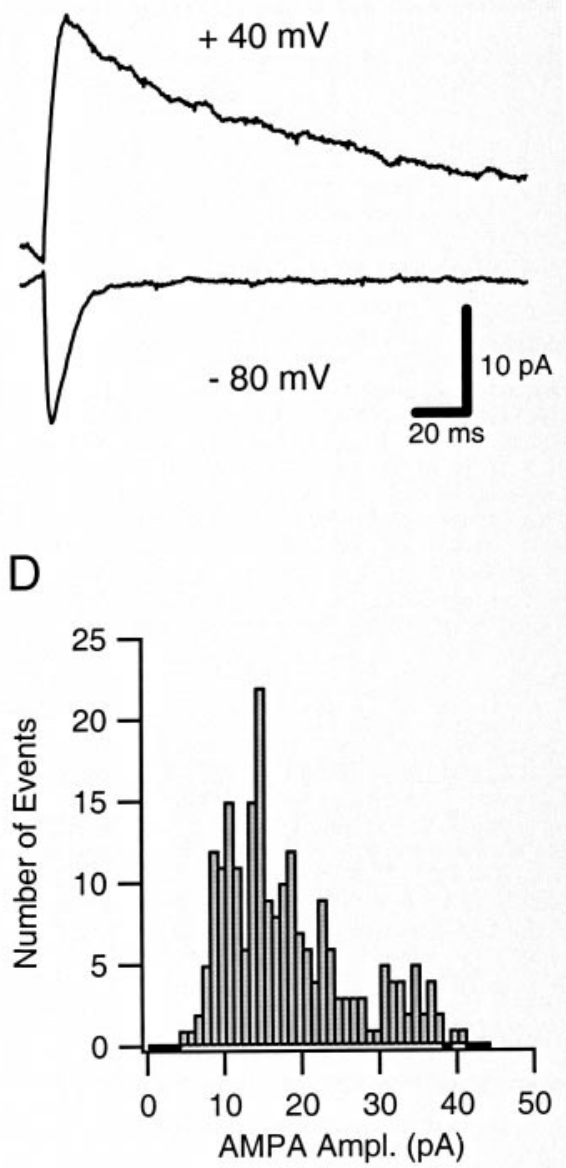

$\mathrm{F}$
Figure 3. AMPA and NMDA sEPSCs in neonatal CA1 pyramidal neurons. $A$, Sample at $+40 \mathrm{mV}$ (top trace) and AMPA sEPSCs recorded at $-80 \mathrm{mV}$ (bottom trace). $B$, Average NMDA ( $n=175$; top trace $)$ and AMPA $(n=218$; bottom trace $)$ sEPSCs from events shown in $A$. $C, D$, Representative amplitude histograms of NMDA $(C ; \mathrm{CV}$ of 0.22$)$ and AMPA ( $D$; CV of 0.38) sEPSCs. Average amplitudes for these recordings were $30.9 \pm$ 1.2 and $17.5 \pm 1.2 \mathrm{pA}$ for NMDA and AMPA sEPSCs, respectively. Noise (root mean square) was 3.5 and $2.1 \mathrm{pA}$, respectively. $E, F$, Histogram of interevent intervals for NMDA $(E)$ and AMPA $(F)$ sEPSCs $(1$ bin is equivalent to $100 \mathrm{msec}$ ). Both histograms were well fitted to a single exponential, indicating that sEPSCs occurred randomly and independently.

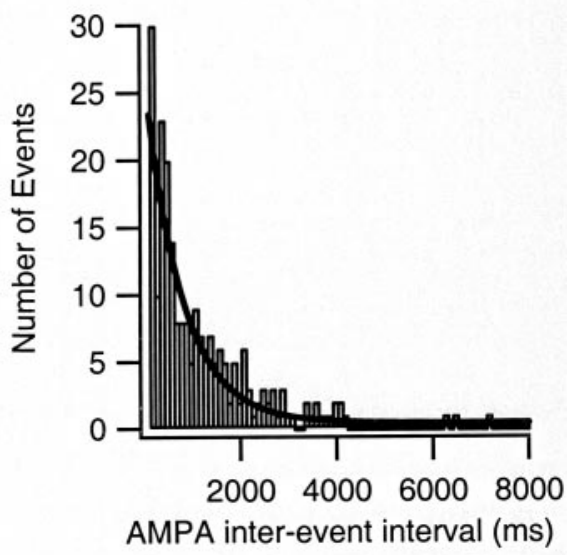

ratio close to one throughout the first postnatal week. When the frequency ratio was averaged for $\mathrm{P} 1-\mathrm{P} 3$ and $\mathrm{P} 6-\mathrm{P} 8$, there was no significant difference between those two groups $(0.89 \pm 0.1$ and $0.83 \pm 0.05$, respectively; $p>0.05$ ) (Fig. $4 C$, inset).

A mismatch in frequency of AMPA and NMDA sEPSCs, attributable to the presence of silent synapses, should be largest on the very first postnatal days (Durand et al., 1996; Hsia et al., 1998). The total numbers of AMPA and NMDA sEPSCs were thus compared for all the cells from P1-P2 rats $(n=8)$, these numbers being 508 and 559, respectively (ratio $=0.9$ ). To estimate the uncertainty of this 0.9 ratio attributable to limited
NMDA sEPSCs for each cell, in which both these sEPSCs were recorded $(n=28)$, is plotted against the postnatal age, showing a presence of TTX). The developmental rates of increase of mEPSC and sEPSC frequencies were $0.09 \pm 0.04$ and $0.13 \pm 0.05$ NMDA sEPSCs, starting from approximately the same value at $\mathrm{P} 1$, increased with much the same slope $(0.13 \pm 0.05$ and $0.13 \pm$ $0.04 \mathrm{~Hz} / \mathrm{d}$, respectively) (Fig. $4 A, B$ ), indicating that the relative contribution of these receptors to spontaneous glutamatergic transmission is constant throughout this period. This is further illustrated in Figure $4 C$ where the frequency ratio for AMPA and 

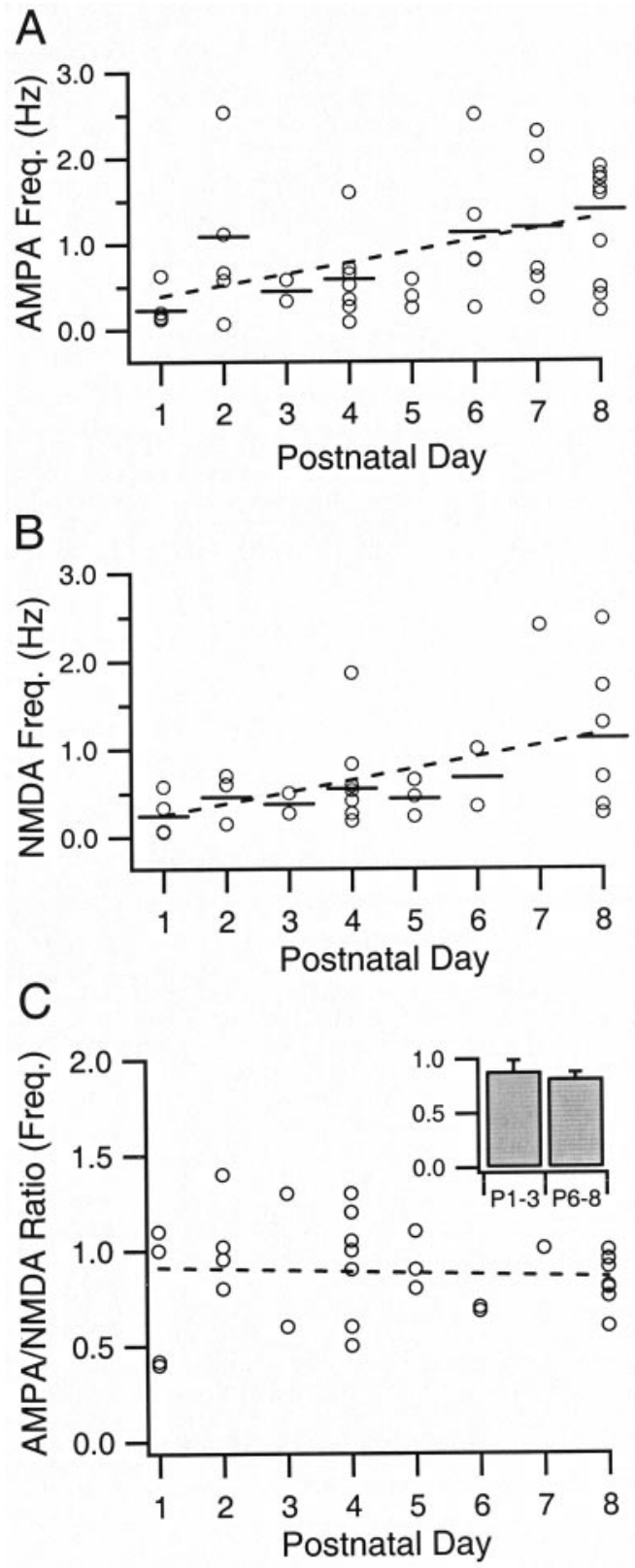

Figure 4. AMPA and NMDA sEPSC frequencies during the first postnatal week. $A$, Frequency of AMPA sEPSCs plotted versus postnatal age. The dashed line represents a linear regression $(r=0.40 ; p<0.05 ; n=40)$. Average value for each postnatal day is represented by a horizontal line. $B$, Frequency of spontaneous NMDA sEPSCs plotted versus postnatal age $(r=0.49 ; p<0.05 ; n=28)$. Note that the $n$ value is smaller for NMDA than for AMPA. This is because an analysis at depolarized potentials was not possible in some cells (see Materials and Methods). C, AMPA/ NMDA ratio for frequency plotted versus postnatal age. No trend was noted over the first postnatal week $(r=-0.07 ; p>0.05 ; n=28)$. Also, the average AMPA/NMDA ratios for P1-P3 and P6-P8 rats were not statistically different (inset; $p>0.05$ ).

number of sampled sEPSCs, we performed a Monte Carlo analysis based on the assumption that the real probability of either an AMPA or NMDA sEPSC occurring was the same (that is an average ratio of 1 ). The parameters were set such that a simulated experiment should, on average, correspond to 550 events. One hundred such simulated experiments gave an SD value of 0.04 (at approximately the average ratio of 1.0 ). The SD value given by
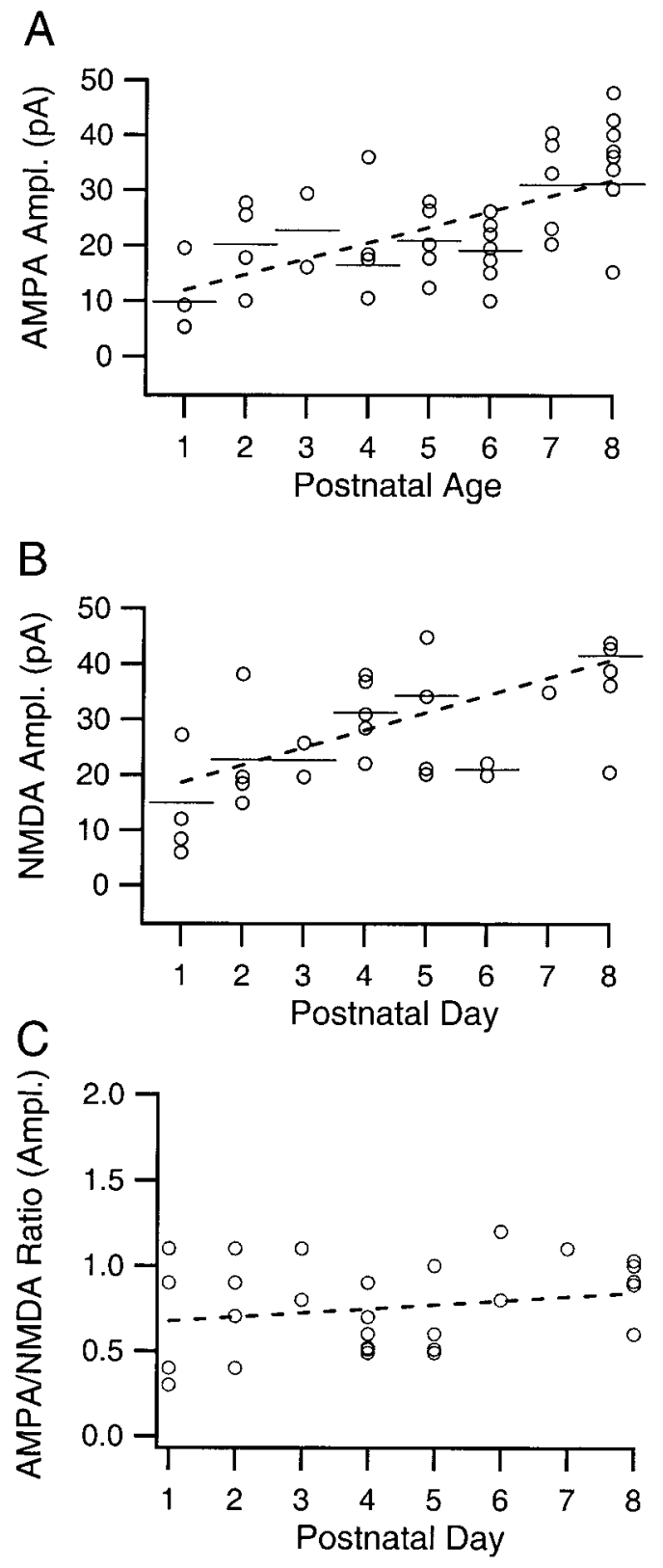

Figure 5. AMPA and NMDA sEPSC amplitudes during the first postnatal week. $A$, Amplitude of AMPA sEPSCs plotted versus postnatal age. Dashed line represents a linear regression $(r=0.62 ; p<0.01 ; n=40)$. Average value for each postnatal day is represented by a horizontal line. $B$, Amplitude of NMDA sEPSCs plotted versus postnatal age $(r=0.58 ; p<$ $0.01 ; n=28)$. $C$, AMPA/NMDA ratio for amplitude plotted versus postnatal age. No trend was noted over the first postnatal week $(r=0.24$; $p>0.05 ; n=28)$.

this simulation then suggests that our experimentally obtained ratio of 0.9 is not consistent with a real value below 0.8 . The present results would then suggest that the proportion of silent synapses is small even at the earliest postnatal days and that it changes little within the first postnatal week.

It can be noted in Figure $4 C$ that the frequency ratio varies between cells as if AMPA transmission dominates in some and NMDA transmission in others. However, as indicated by varying the number of events in the Monte Carlo simulation, most of this experimental variation seems to be explained by the limited number of sampled sEPSCs. 

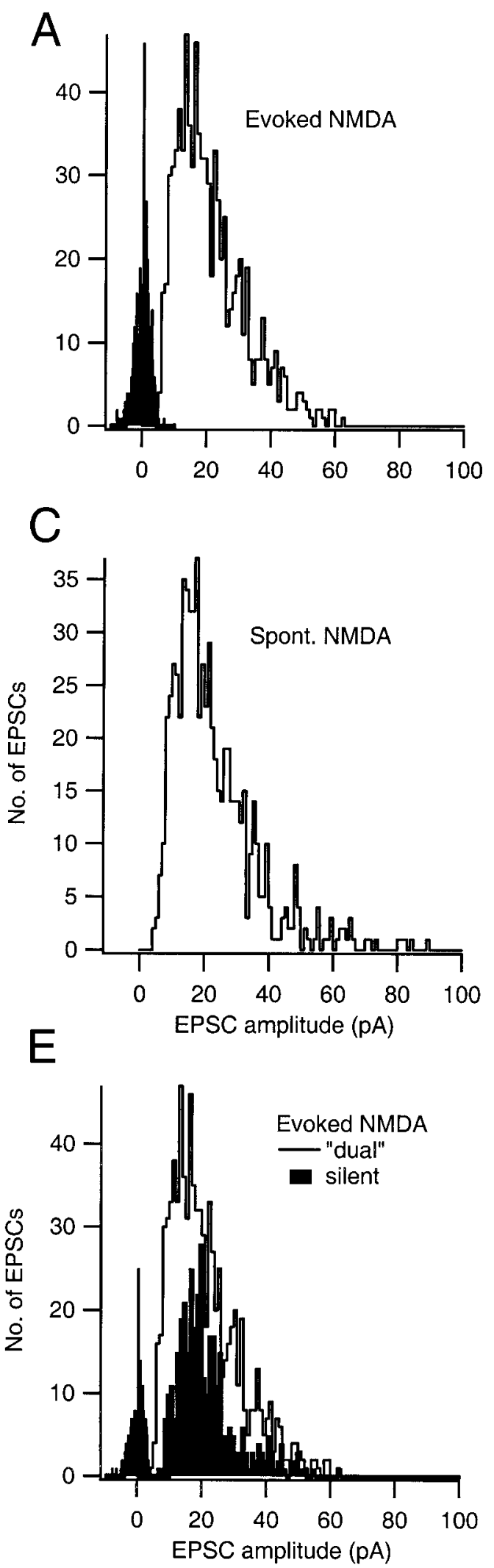

B

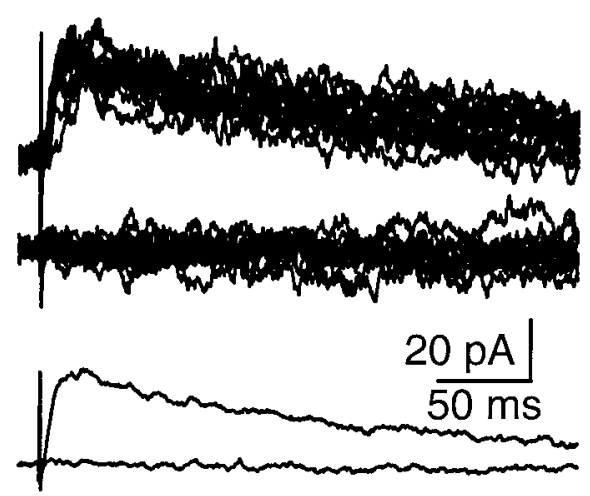

D
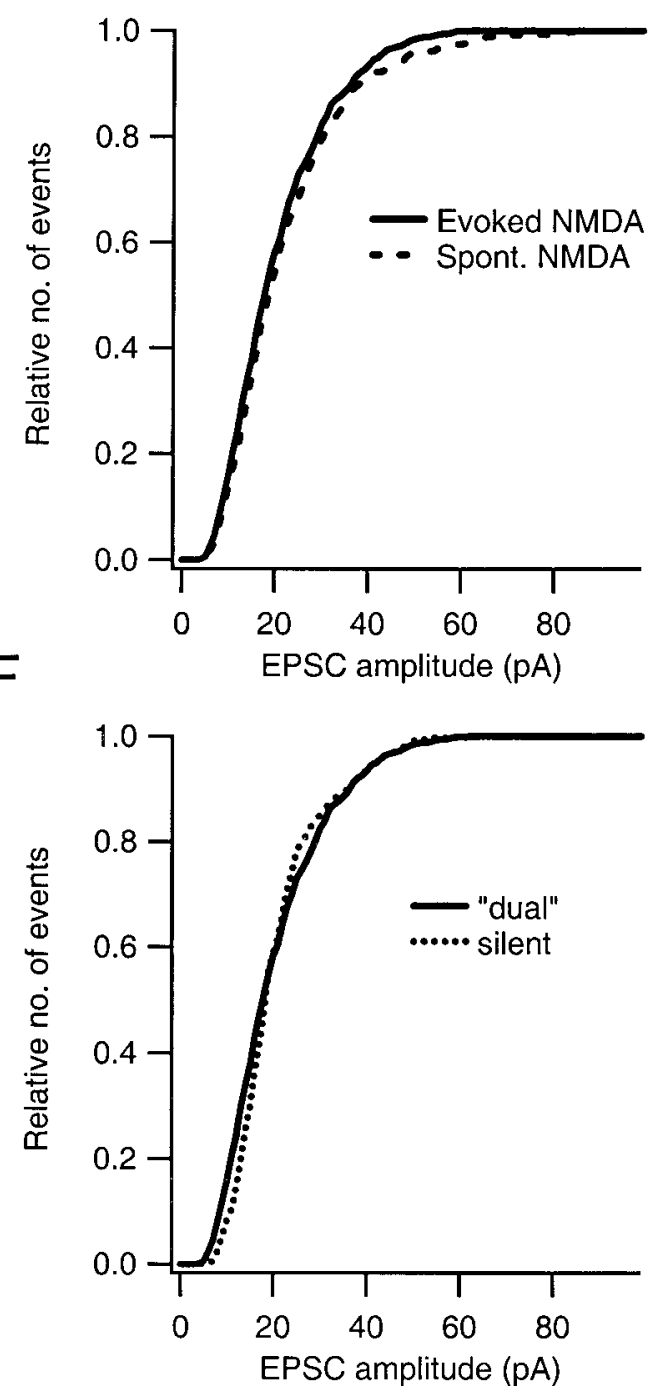

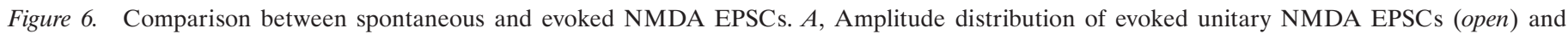

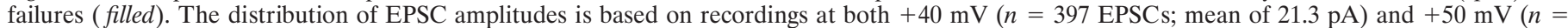

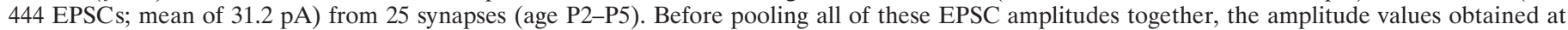

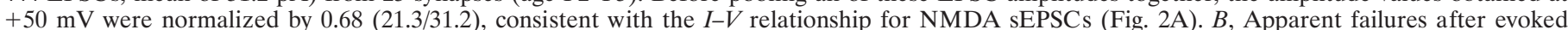

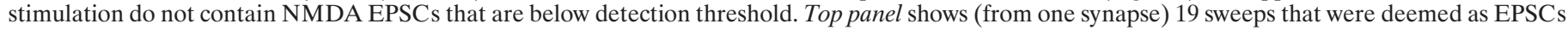

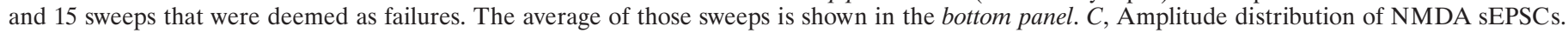




\section{Quantal amplitude and variation of SEPSCs}

The results above show a parallel increase in the frequency of AMPA and NMDA sEPSCs over the first 8 postnatal days. Over this period, there was also a parallel increase in the average amplitude of AMPA and NMDA sEPSCs (Fig. 5A,B). To control for variations between cells, the average amplitude of the AMPA sEPSCs (in each cell) was normalized to that of the NMDA sEPSCs. This amplitude ratio did not exhibit any significant developmental trend $(r=0.24 ; p>0.05 ; n=28)$ (Fig. $5 C$ ). As shown in Figure 3,C and $D$, there was (for any given cell) a substantial variation in the amplitude of individual sEPSCs. The $\mathrm{CV}$ for NMDA sEPSCs among the cells averaged $0.28 \pm 0.03$ $(n=28)$, a value that was significantly smaller than the average CV for AMPA sEPSCs $(0.48 \pm 0.03 ; n=40)$. This difference is consistent with the idea that a quanta of glutamate more efficiently activates NMDA receptors than AMPA receptors (McAllister and Stevens, 2000; Hanse and Gustafsson, 2001). Over the first 8 postnatal days, there was a significant increase, approximately a doubling, in the CV of both AMPA $(r=0.49 ; p<0.01$; $n=40)$ and NMDA $(r=0.59 ; p<0.01 ; n=28)$ sEPSCs .

These increases in frequency, amplitude, and $\mathrm{CV}$ of both AMPA and NMDA sEPSCs during the first 8 postnatal days would be consistent with an increase in the number of release sites connecting individual CA3 and CA1 pyramidal cells. However, as shown in Figure 1, this conclusion is unlikely because the amplitude ratio between sEPSCs recorded in the presence and absence of TTX was close to one throughout this developmental period.

\section{Comparison between spontaneous and evoked NMDA sEPSCs}

The above results with sEPSCs point to a very low number of silent synapses in the neonatal period. Previous studies, using evoked EPSCs, have indicated that considerably more than onehalf of the glutamatergic synapses are silent at this developmental stage (Durand et al., 1996; Liao and Malinow, 1996). The detection of unitary events would be expected to be more precise for evoked responses (because it is known when they occur, if they occur). Thus, a comparison between the amplitude distributions of NMDA sEPSCs with that of evoked unitary NMDA EPSCs would be a test of whether we actually have achieved maximal detection of NMDA sEPSCs. Thus, are there small NMDA sEPSCs that have gone undetected leading to a falsely high AMPA/NMDA frequency ratio?

Evoked unitary NMDA EPSCs (see Materials and Methods) from 25 dual synapses were pooled together ( $n=841$ EPSCs), and the resulting amplitude distribution is shown in Figure $6 A$. These cells $(n=25)$ were taken from P2-P5 rats, and their input resistance and capacitance averaged $0.98 \pm 0.08 \mathrm{M} \Omega$ and $17.7 \pm$ $0.9 \mathrm{pF}$, respectively. The distribution of evoked unitary NMDA EPSCs is skewed toward smaller amplitudes and has a mean \pm SD of $21.3 \pm 10.9 \mathrm{pA}$. The amplitude distribution for sweeps deemed as failures is symmetrical at approximately zero (Fig. $6 A$ ), and averages of failure sweeps did not reveal any small NMDA component (Fig. 6B). On the average, the amplitude measurement of failure sweeps (see Materials and Methods) was $-0.15 \pm 0.45 \mathrm{pA}$ (mean $\pm \mathrm{SD} ; n=25)$. These findings indicate an accurate separation between failures and EPSCs. For comparison, a distribution of NMDA sEPSCs was obtained by pooling such sEPSCs from 16 cells, also taken from P2-P5 rats (Fig. 6C). Input resistance and capacitance of these cells were $0.83 \pm 0.05$ $\mathrm{M} \Omega$ and $16.9 \pm 1.1 \mathrm{pF}$, respectively $(n=16)$. The sEPSCs averaged $22.7 \pm 13 \mathrm{pA}$ (mean $\pm \mathrm{SD}$ ), that is, very similar values to those for the evoked EPSCs. As further shown by the overlap between the cumulative representations of these distributions (Fig. 6D), our detected NMDA sEPSCs do not differ from the evoked ones.

It may be argued that evoked unitary NMDA EPSCs from dual synapses are not representative for those generated at silent ones. The amplitude distribution of evoked unitary NMDA EPSCs $(n=360)$ from five synapses that were found to lack evoked AMPA signaling (see Material and Methods) is plotted in Figure $6 E$ together with the amplitude distribution from the dual synapses shown in Figure $6 A$. These NMDA EPSCs averaged 21.6 $\mathrm{pA}$, which is a value very close to that of the dual ones $(21.3 \mathrm{pA}$; see above). As shown from the amplitude distributions in Figure $6 E$ and their cumulative representations in Figure $6 F$, NMDA EPSCs from dual synapses seem representative also for NMDA EPSCs from the silent ones. These comparisons between evoked unitary and sEPSCs substantiate that recordings at $+40 \mathrm{mV}$ provide maximal frequency detection of NMDA sEPSCs both from dual and silent synapses in neonatal hippocampal pyramidal neurons.

\section{Effect of temperature and divalent ions on AMPA and NMDA signaling}

To test the possibility that the recording temperature is affecting the AMPA/NMDA ratios, we performed experiments at room temperature $\left(18-20^{\circ} \mathrm{C}\right)$. As shown in Figure $7 A$, reducing temperature from our normal one $\left(30-32^{\circ} \mathrm{C}\right)(n=19$; age matched to low temperature group, P2-P7) to $18-20^{\circ} \mathrm{C}$ did not significantly affect the AMPA/NMDA sEPSC frequency ratio (from $0.89 \pm$ 0.10 at $30-32^{\circ} \mathrm{C}$ to $0.84 \pm 0.26$ at $\left.18-20^{\circ} \mathrm{C} ; n=4\right)$ or the amplitude ratio (from $0.77 \pm 0.24$ at $30-32^{\circ} \mathrm{C}$ to $0.90 \pm 0.17$ at $\left.18-20^{\circ} \mathrm{C} ; n=4\right)$. The average amplitudes of both AMPA (19 \pm $3 \mathrm{pA} ; n=4)$ and NMDA (20 $\pm 3 \mathrm{pA} ; n=4)$ sEPSCs were not significantly different from those at normal temperature $(22 \pm 2$ and $26 \pm 3 \mathrm{pA}$, respectively), indicating that the detectability of the sEPSCs, and thus the estimation of the frequency ratio, would not be different at the two temperatures.

Extracellular divalent ions affect synaptic function in various ways, including release probability and NMDA receptor function. Therefore, we tested whether the extracellular $\mathrm{Ca}^{2+}$ and $\mathrm{Mg}^{2+}$ concentrations influenced the AMPA/NMDA frequency ratio. Changing the extracellular $\mathrm{Ca}^{2+} / \mathrm{Mg}^{2+}$ concentration (in $\mathrm{mM}$ ) ratio from 4:4 to either 2:2 or 4:0 ( $n=5$ for both groups) did not significantly affect the AMPA/NMDA frequency ratio $(p>0.05)$ (Fig. $7 B$ ). Together, these findings indicate that the recording temperature, intracellular $\mathrm{Mg}^{2+}$, or extracellular divalent ion

\footnotetext{
The distribution is based on recordings at $+40 \mathrm{mV}(n=705$ sEPSCs; mean of $22.7 \mathrm{pA})$ from 16 cells (age P2-P5). $D$, Cumulative representations of the amplitude distribution of evoked NMDA EPSCs (shown in $A$, solid line) and of NMDA sEPSCs (shown in $C$, dashed line). $E$, Amplitude distribution of evoked unitary NMDA EPSCs ( filled) as well as failures ( filled) from five silent synapses. The amplitude distribution of evoked unitary NMDA EPSCs from dual synapses shown in $A$ is replotted in the background for comparison. The distribution of EPSC amplitudes from the silent synapses is based on recordings at $+40 \mathrm{mV}(n=360$ EPSCs; mean of $21.6 \mathrm{pA}) . F$, Cumulative representations of the amplitude distributions of evoked NMDA EPSCs from dual (solid line) and silent (dashed line) synapses.
} 

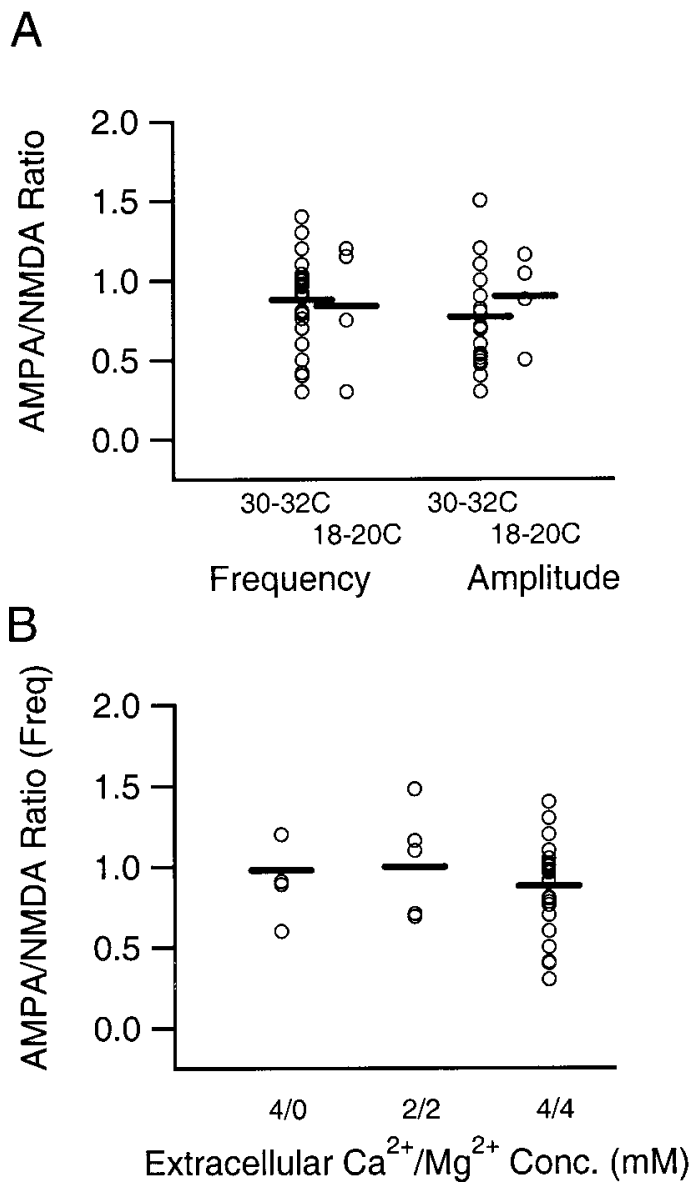

Figure 7. Effects of recording temperature and divalent ions on the relative contribution of AMPA and NMDA sEPSCs. $A$, Effect of recording temperatures on AMPA/NMDA ratio. Changing the bath temperature from $30-32^{\circ} \mathrm{C}$ to $18-20^{\circ} \mathrm{C}$ did not change AMPA/NMDA ratio for either frequency or amplitude $(p>0.05)$. B. Changing the $\mathrm{Ca}^{2+} / \mathrm{Mg}^{2+}$ ratio from $4: 4$ to either $2: 2$ or $4: 0$ did not change the AMPA/NMDA ratio for frequency $(p>0.05)$.

concentration, have not biased the relative frequency detection of AMPA and NMDA sEPSCs.

\section{DISCUSSION}

The idea that a critical step in the maturation of glutamatergic synapses is an activity-dependent incorporation of AMPA receptors at originally silent, or pure NMDA, synapses, has received considerable attention, as well as experimental supports (Isaac et al., 1995; Liao et al., 1995; Durand et al., 1996; Liao and Malinow, 1996; Hsia et al., 1998). However, other studies have indicated that most nascent glutamatergic synapses maintain both AMPA and NMDA receptors postsynaptically (Tyzio et al., 1999; Friedman et al., 2000; Gasparini et al., 2000; Renger et al., 2001). Here the relative number of silent synapses on neonatal CA1 pyramidal neurons was quantified using spontaneous (instead of evoked) AMPA and NMDA EPSCs, demonstrating an almost equal contribution of those sEPSCs throughout the neonatal period. Our results thus indicate that the default mode of signaling at nascent glutamatergic synapses is dual rather than silent.

The conclusion of an almost equal contribution of AMPA and NMDA sEPSCs relies on an accurate detection of these events. This was tested for in several ways. By constructing frequencyvoltage relationships, AMPA and NMDA sEPSCs frequency detection was found to saturate at -80 and $+40 \mathrm{mV}$, respectively, in these neonatal pyramidal neurons. At $-80 \mathrm{mV}$, cyclothiazide, causing a doubling of AMPA sEPSC amplitude, produced no increased detection of these sEPSCs, substantiating an accurate detection of them. Because evoked unitary NMDA EPSCs from both dual and silent synapses were shown to be accurately detected at $+40 \mathrm{mV}$, these EPSCs were used to further evaluate maximal detection of NMDA sEPSCs. Essentially equal amplitude distributions of evoked and spontaneous NMDA EPSCs were found, strongly indicating that small NMDA sEPSCs were not missed.

The relative occurrence of silent synapses in the neonatal hippocampus has been assessed previously using evoked synaptic transmission (Durand et al., 1996; Liao and Malinow, 1996; Hsia et al., 1998). Although these studies have generated different estimates, they have all found evidence for a substantial fraction $(50-80 \%)$ of silent synapses in the early neonatal period (Isaac et al., 1995; Liao et al., 1995). The question then arises what may underlie the discrepancy vis-à-vis the present results. A main difference is the manner by which the synapses were activated. It may be conceived that when evoked synaptic transmission is used, sensitive synapses may become "silenced" during the procedure of establishing the criteria for silent synapses. This procedure has most commonly consisted of a relatively high-frequency (0.1-2 $\mathrm{Hz}$ ) stimulation of the synapse before the demonstration of the absence of AMPA responses. During this stimulation, there is little control of what might happen to a putative AMPA component of the evoked response. Moreover, because those previous studies often has intended to induce AMPA signaling at previously silent synapses, a low concentration of calcium chelator in the intracellular solution has been used. In contrast, here the EGTA concentration was kept high, and synapses were active at a very low frequency. The average frequency of sEPSCs of 0.5-1 $\mathrm{Hz}$ was probably distributed among hundreds of synapses, and, under these conditions, a given synapse is not likely to undergo activity-dependent changes in efficacy.

There is much evidence suggesting that AMPA signaling of nascent glutamatergic synapses is particularly prone for depression in response to a relatively mild stimulation. Gasparini et al. (2000) showed that the success rate of AMPA EPSCs in the neonatal hippocampal slice preparation drops substantially when increasing the stimulation frequency from 0.025 to $1 \mathrm{~Hz}$. Moreover, even as few as 6-20 paired stimuli (at $0.1 \mathrm{~Hz}$ ) induce significant long-term depression (LTD) at CA3-CA1 synapses of 7- to 12-d-old rats (Wasling et al., 2002). Whether the depression in these studies only affected AMPA transmission was, however, not examined. Nonetheless, other studies have indicated mechanisms for selective depression of AMPA transmission at nascent hippocampal synapses. Vesicle fusion at glutamatergic synapses in hippocampal cultures matures such that the glutamate concentration profile in the synaptic cleft initially is only sufficient to activate NMDA receptors, whereas it later in development activates both AMPA and NMDA receptors (Renger et al., 2001). The mode of vesicle fusion, restricted fusion (kiss-and-run fusion) versus unrestricted fusion, may be subject to activitydependent modulation (Choi et al., 2000). An LTD, expressed as a downregulation of postsynaptic AMPA receptors, constitutes another possibility for an activity-dependent selective reduction of AMPA transmission (for review, see Carroll et al., 2001).

In addition to the very low frequency at which synapses were active in the present study, there are several other differences compared with previous studies of nascent glutamatergic syn- 
apses. However, none of these differences appear to be of major importance in explaining the presently found very low incidence of silent synapses. First, the present study was conducted at a recording temperature of $30-32^{\circ} \mathrm{C}$. Low temperatures $\left(20-22^{\circ} \mathrm{C}\right)$ impair the AMPA-mediated transmission relative to the NMDAmediated one (Asztely et al., 1997; Gasparini et al., 2000), and most previous studies demonstrating silent synapses have been conducted at room temperatures (Isaac et al., 1995; Liao et al., 1995; Durand et al., 1996; Liao and Malinow, 1996; Hsia et al., 1998). However, the same relative frequency of AMPA and NMDA sEPSCs was presently found at room temperature and at $30-32^{\circ} \mathrm{C}$. Moreover, silent synapses can also be identified also at higher temperatures (Hanse and Gustafsson, 2001; Montgomery et al., 2001; present study). Second, to prevent synchronous activity, we used high concentrations of extracellular $\mathrm{Ca}^{2+}$ and $\mathrm{Mg}^{2+}$. However, control experiments using lower concentrations of these divalent ions did not change the AMPA/NMDA ratio, indicating that also this experimental parameter is of little importance.

It may be conceived that silent synapses participate to a much lower extent than the nonsilent ones to action potentialdependent and -independent spontaneous release. However, because silent and nonsilent synapses do not differ with respect to release probability to evoked release (Hanse and Gustafsson, 2001), one may not expect them to differ with respect to the spontaneous release (Prange and Murphy, 1999). Moreover, when boosting release using high $\mathrm{Ca}^{2+}$-zero $\mathrm{Mg}^{2+}$ solution, the AMPA/NMDA frequency ratio was unaffected.

Although the present results provide no indication of an early synaptic maturation consisting of a relative growth of AMPA signaling over the NMDA one, we did find an increase in both frequency and amplitude of AMPA and NMDA sEPSCs during the first postnatal week. The increased frequency is consistent with morphological data showing an increase of the dendritic tree, as well as the number of synapses per cell during this period (Pokorny and Yamamoto, 1981; Steward and Falk, 1991; LopezGallardo and Prada, 2001). The parallel increase in amplitude of AMPA and NMDA sEPSCs is easiest explained by a parallel increase in the number of AMPA and NMDA receptors, which, in turn, may reflect an increase in the average size of the synapses (Takumi et al., 1999). Concomitant with the increase in amplitude, there was also an increase in the CV of the sEPSC amplitudes on a given cell. The average CV for AMPA and NMDA sEPSCs in the present material was quite close to average values obtained previously from evoked stimulation of individual glutamatergic synapses at this age (quantal variability of 0.39 and 0.28 , respectively) (Hanse and Gustafsson, 2001). The CV value for sEPSCs on a given cell should, however, reflect both the difference in mean quantal size between synapses and the quantal variability within synapses. Thus, the similarity in $\mathrm{CV}$ between evoked unitary and spontaneous EPSCs suggests that either quantal variability is substantially lower during spontaneous transmission compared with evoked transmission and/or the mean quantal size is kept relatively constant at synapses on a given postsynaptic cell (cf. Liu and Tsien, 1995). The latter possibility would suggest that the presently found increase in $\mathrm{CV}$ of sEPSCs with development is explained by a larger divergence of synaptic mean quantal sizes on a given cell during the first postnatal week. Interestingly, when comparing mEPSCs in the CA1 region from neonatal $(<2$ weeks) and young adult $(>2$ months) animals, Hsia et al. (1998) found a significant reduction in CV. Assuming a coupling between synaptic morphology and mean quantal size, this initial increase and later decrease in $\mathrm{CV}$ of mEPSCs appears consistent with morphological data on synaptic maturation (Fiala et al., 1998). Directly after birth, glutamatergic synapses are mainly shaft or filopodial synapses. During the second postnatal week, spine synapses appear, whereas shaft and filopodial synapses start to decrease. To what extent the developmental change in synaptic structure and function is governed by neuronal activity remains to be tested.

In conclusion, the present results argue that AMPA and NMDA receptor-mediated signaling emerges concomitantly, and not sequentially, at hippocampal glutamatergic synapses. Together with previous findings (Tyzio et al., 1999; Friedman et al., 2000; Gasparini et al., 2000; Renger et al., 2001), we propose that the vast majority of hippocampal glutamatergic synapses are born "mature" in the sense that they express both functional AMPA and NMDA receptors.

\section{REFERENCES}

Asztely F, Erdemli G, Kullmann DM (1997) Extrasynaptic glutamate spillover in the hippocampus: dependence on temperature and the role of active glutamate uptake. Neuron 18:281-293.

Ben Ari Y, Cherubini E, Corradetti R, Gaiarsa JL (1989) Giant synaptic potentials in immature rat CA3 hippocampal neurones. J Physiol (Lond) 416:303-325.

Carroll RC, Beattie EC, von Zastrow M, Malenka RC (2001) Role of AMPA receptor endocytosis in synaptic plasticity. Nat Rev Neurosci 2:315-324.

Choi S, Klingauf J, Tsien RW (2000) Postfusional regulation of cleft glutamate concentration during LTP at "silent synapses." Nat Neurosci 3:330-336.

Cottrell JR, Dube GR, Egles C, Liu G (2000) Distribution, density, and clustering of functional glutamate receptors before and after synaptogenesis in hippocampal neurons. J Neurophysiol 84:1573-1587.

Durand GM, Kovalchuk Y, Konnerth A (1996) Long-term potentiation and functional synapse induction in developing hippocampus. Nature 381:71-75.

Fiala JC, Feinberg M, Popov V, Harris KM (1998) Synaptogenesis via dendritic filopodia in developing hippocampal area CA1. J Neurosci 18:8900-8911.

Friedman HV, Bresler T, Garner CC, Ziv NE (2000) Assembly of new individual excitatory synapses: time course and temporal order of synaptic molecule recruitment. Neuron 27:57-69.

Garaschuk O, Hanse E, Konnerth A (1998) Developmental profile and synaptic origin of early network oscillations in the CA1 region of rat neonatal hippocampus. J Physiol (Lond) 507:219-236.

Gasparini S, Saviane C, Voronin LL, Cherubini E (2000) Silent synapses in the developing hippocampus: lack of functional AMPA receptors or low probability of glutamate release? Proc Natl Acad Sci USA 97:9741-9746.

Hanse E, Gustafsson B (2001) Quantal variability at glutamatergic synapses in area CA1 of the rat neonatal hippocampus. J Physiol (Lond) 531:467-480.

Hsia AY, Malenka RC, Nicoll RA (1998) Development of excitatory circuitry in the hippocampus. J Neurophysiol 79:2013-2024.

Isaac JT, Nicoll RA, Malenka RC (1995) Evidence for silent synapses: implications for the expression of LTP. Neuron 15:427-434.

Kullmann DM (1994) Amplitude fluctuations of dual-component EPSCs in hippocampal pyramidal cells: implications for long-term potentiation. Neuron 12:1111-1120.

Liao D, Malinow R (1996) Deficiency in induction but not expression of LTP in hippocampal slices from young rats. Learn Mem 3:138-149.

Liao D, Hessler NA, Malinow R (1995) Activation of postsynaptically silent synapses during pairing-induced LTP in CA1 region of hippocampal slice. Nature 375:400-404.

Liao D, Zhang X, O’Brien R, Ehlers MD, Huganir RL (1999) Regulation of morphological postsynaptic silent synapses in developing hippocampal neurons. Nat Neurosci 2:37-43.

Liu G, Tsien RW (1995) Synaptic transmission at single visualized hippocampal boutons. Neuropharmacology 34:1407-1421.

Lopez-Gallardo M, Prada C (2001) Spatial and temporal patterns of morphogenesis of hippocampal pyramidal cells: study in the early postnatal rat. Hippocampus 11:118-131.

McAllister AK, Stevens CF (2000) Nonsaturation of AMPA and NMDA receptors at hippocampal synapses. Proc Natl Acad Sci USA 97:6173-6178.

Montgomery JM, Pavlidis P, Madison DV (2001) Pair recordings reveal all-silent synaptic connections and the postsynaptic expression of longterm potentiation. Neuron 29:691-701. 
Niu YP, Xiao MY, Wigstrom H (1998) Variability of AMPA and NMDA receptor mediated responses in CA1 pyramidal cells of young rats. Brain Res 800:253-259.

Petralia RS, Esteban JA, Wang YX, Partridge JG, Zhao HM, Wenthold RJ, Malinow R (1999) Selective acquisition of AMPA receptors over postnatal development suggests a molecular basis for silent synapses. Nat Neurosci 2:31-36.

Pokorny J, Yamamoto T (1981) Postnatal ontogenesis of hippocampal CA1 area in rats. I. Development of dendritic arborisation in pyramidal neurons. Brain Res Bull 7:113-120.

Prange O, Murphy TH (1999) Correlation of miniature synaptic activity and evoked release probability in cultures of cortical neurons. J Neurosci 19:6427-6438.

Raastad M (1995) Extracellular activation of unitary excitatory synapses between hippocampal CA3 and CA1 pyramidal cells. Eur J Neurosci 7:1882-1888.

Renger JJ, Egles C, Liu G (2001) A developmental switch in neurotrans- mitter flux enhances synaptic efficacy by affecting AMPA receptor activation. Neuron 29:469-484.

Steward O, Falk PM (1991) Selective localization of polyribosomes beneath developing synapses: a quantitative analysis of the relationships between polyribosomes and developing synapses in the hippocampus and dentate gyrus. J Comp Neurol 314:545-557.

Stevens CF, Wang Y (1995) Facilitation and depression at single central synapses. Neuron 14:795-802.

Takumi Y, Ramirez-Leon V, Laake P, Rinvik E, Ottersen OP (1999) Different modes of expression of AMPA and NMDA receptors in hippocampal synapses. Nat Neurosci 2:618-624.

Tyzio R, Represa A, Jorquera I, Ben-Ari Y, Gozlan H, Aniksztejn L (1999) The establishment of GABAergic and glutamatergic synapses on CA1 pyramidal neurons is sequential and correlates with the development of the apical dendrite. J Neurosci 19:10372-10382.

Wasling P, Hanse E, Gustafsson B (2002) Long-term depression in the developing hippocampus: low induction threshold and synapse nonspecificity. J Neurosci 22:1823-1830. 